\title{
LA GARANTÍA DE INDEMNIDAD EN CHILE: ANÁLISIS NORMATIVO Y COMPARATIVO DESDE EL DERECHO COMPARADO Y EL COMMON LAW*
}

\section{GONZALO MARTÍNEZ MERINo**}

\begin{abstract}
RESUMEN: El presente trabajo desarrolla la garantía de indemnidad en el ordenamiento jurídico chileno a través de un análisis desde el Derecho comparado, especialmente desde la doctrina constitucional española y el common law estadounidense. Tiene por objeto describir la importancia que tuvo en nuestro país la entrada en vigencia de la Ley 20.087 y la necesidad de un reconocimiento legal de la garantía de indemnidad, explicando brevemente el contexto de su utilización, su origen conceptual y desarrollo normativo, finalizando por medio de un análisis comparativo de los elementos básicos o definitorios de la garantía, mencionando resumidamente casos concretos. Se busca dilucidar, por tanto, dos cuestiones primarias: el origen y entrada en vigencia de la garantía en Chile, que defino como tardía y semifortuita, junto con el desarrollo actual de la indemnidad y la configuración de los elementos básicos realizados por los Tribunales de Justicia chilenos.
\end{abstract} boral.

PALABRAS CLAVE: Garantía de indemnidad - represalia - justicia la-

\section{INDEMNITY GUARANTEE IN CHILE: NORMATIVE AND COMPARATIVE ANALYSIS FROM COMPARATIVE LAW AND THE COMMON LAW}

ABSTRACT: This paper develops the indemnity guarantee in the Chilean legal system through an analysis from comparative law, especially from the Spanish constitutional doctrine and the American common law. The objective is to describe the significance in our country the enactment of Law 20,087 and the need of a legal recognition of indemnity guarantee, briefly explaining the context of its use, its conceptual origin and development policy, ending with a comparative analysis and defining the

\footnotetext{
* Fecha de recepción: 2 de febrero de 2012. Fecha de aceptación: 25 de junio de 2012

** Abogado. Licenciado en Ciencias Jurídicas por la Universidad Católica del Norte. Correo Electrónico: gonzaloalberto.martinez@gmail.com
} 
basic elements of the guarantee, briefly mentioning specific cases. It seeks to clarify two primary issues: the origin and entry into force of the guarantee in Chile, which I define as semi late and fortuitous, along with the current development of the indemnity and the configuration of the basic elements developed by the Chilean Justice Courts.

KEY WORDS: Indemnity guarantee - retaliation - labor justice.

\section{1) INTRODUCCIÓN Y CONTEXTUALIZACIÓN}

La garantía de indemnidad irrumpe en el ordenamiento jurídico chileno a principios del año 2006 con la entrada en vigencia de la Ley 20.087 que institucionaliza, mediante un procedimiento novedoso, la tutela de los derechos fundamentales del trabajador en la relación laboral. Cabe hacer presente que este procedimiento, que reconoce explícitamente la garantía de indemnidad en el Código del Trabajo, "es más que una reforma meramente adjetiva, sino una enmienda realmente sustancial, que constituye la base de un verdadero derecho procesal del trabajo en nuestro

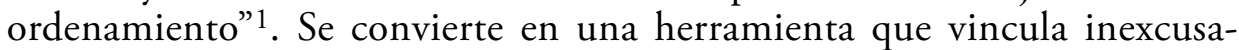
blemente los derechos fundamentales del trabajador como persona y sujeto de derecho con los tribunales de justicia. Ahora, si bien la garantía de indemnidad no es un derecho fundamental reconocido expresamente en la Constitución (aunque fundado en el derecho a la tutela judicial efectiva), es un reconocimiento legal a una situación de facto, cuya substancia particular es el derecho que tiene el trabajador a no ser objeto de represalias laborales ${ }^{2}$.

Previo a la entrada en vigencia del procedimiento de tutela laboral, la realidad chilena estaba caracterizada por la falta de un rol activo por parte de los tribunales de justicia sobre la materia ${ }^{3}$. El trabajador no contaba con herramientas concretas para recurrir a los órganos judiciales en caso de vulneración de derechos fundamentales en el trabajo, creándose un abismo entre el Derecho del trabajo chileno y la realidad, constituyendo

Gamonal, Sergio (2009) El procedimiento de tutela de derechos laborales. Santiago, LegalPublishing Chile, $4^{\mathrm{a}}$ ed. $\mathrm{p} 1$.

2 El artículo 483 inciso $3^{\circ}$ del Código del Trabajo señala que "Se entenderá que los derechos y garantías a que se refieren los incisos anteriores resultan lesionados cuando el ejercicio de las facultades que la ley le reconoce al empleador limita el pleno ejercicio de aquellas sin justificación suficiente, en forma arbitraria o desproporcionada, o sin respeto a su contenido esencial. En igual sentido se entenderán las represalias ejercidas en contra de trabajadores, en razón o como consecuencia de la labor fiscalizadora de la Dirección del Trabajo o por el ejercicio de acciones judiciales.

3 Canmaño, Eduardo (2007) El derecho a la no discriminación en el empleo. Santiago, LexisNexis, 2a ed. p 13. 
lo que un autor calificó como un "triste y desolado escenario" ${ }^{4}$. Solo con la aprobación del procedimiento de tutela laboral al que hago referencia, el Estado se hizo cargo de "una demanda histórica" 5 del trabajador en el área laboral, además de lograr un reconocimiento explícito a los principios y valores de la Carta Fundamental en el iter laboral.

Este reconocimiento explícito de los principios de la Carta Fundamental en las relaciones particulares tiene su origen en el Derecho continental europeo, con la llamada doctrina de la horizontalidad de derechos u Horizontalwirkung ${ }^{6}$. En lo referido al Derecho del trabajo, de la aplicabilidad de las normas fundamentales en el iter laboral nace la doctrina de la ciudadanía en la empresa, aquellos derechos civiles y políticos que tiene el trabajador como ciudadano en la empresa -o los denominados derechos fundamentales inespecíficos- que deben ser respetados por el empleador independiente de la relación de poder asimétrica que los liga.

Esta doctrina, la idea de eficacia horizontal de los derechos fundamentales y la impregnación de la Constitución en nuestro ordenamiento jurídico fue un proceso "algo traumático" 7 , cuestión expresada en la propia entrada en vigencia de la ley 20.087. Si bien había un consenso general en la importancia del proyecto y la necesidad de modernización en el área laboral por los actores políticos, el procedimiento de tutela y la idea de incluir derechos fundamentales inespecíficos en el código fue bastante debatida ${ }^{8}$. De hecho, la aprobación final de la Ley 20.087 en

4 CaAmaño (2007) 13, citando a UGARTE, José Luis, "Los derechos fundamentales y relaciones laborales: en el mundo de las palabras", Anuario de Derecho del Trabajo y Seguridad Social No3/2004, Derechos Fundamentales, Homenaje al Profesor Patricio Novoa Fuenzalida, Sociedad Chilena de Derecho de Trabajo y de Seguridad Social, p. 21.

5 Historia de la Ley No20.087. Boletín No 3.367-13. "Sustituye el procedimiento laboral contemplado en el libro V del Código del Trabajo”, p 392. Disponible en www.bcn.cl Gamonal (2009) 3.

Ugarte Cataldo, José (2007) "La tutela de derechos fundamentales y el derecho del trabajo: de zorro a erizo”. En Revista de Derecho (Valdivia) Volumen XX-diciembre 2007 p. 55

Expresión de ella es la oposición generalizada que tuvo el diputado Nicolás Monckeberg (RN) entre sus colegas en la discusión en sala de la Cámara de Diputados, referido al Segundo Informe Comisión de Trabajo: "Antes de finalizar mi intervención, quiero señalar que la discusión política en la Comisión fue intensa y que, en el fragor del debate, constaté que al diputado seńor Monckeberg no le es amigable el concepto de derechos laborales, pues se opuso tenazmente a votar afirmativamente los artículos que apuntaban a agilizar el procedimiento laboral en todos sus párrafos.” Diputada Sra. Ximena Vidal (PPD), Historia de la LEY No 20.087 p 324

"Por eso, no es razonable el planteamiento del diputado señor Monckeberg. Si el año pasado o antepasado hubiese preguntado por qué no hay nuevos tribunales laborales y por qué no hay un nuevo procedimiento, se podría haber entendido su alegato, pero lo hace en medio de la tramitación de dos proyectos significativos, que cambian cualitativamente la institucionalidad laboral. No se entiende la disposición anímica en que se encuentra, porque todos debiéramos alegrarnos de que se aprueben estos proyectos”. Diputado Sr. Sergio Aguiló (PS). Historia de la Ley No 20.087 p. 329.

"En ese sentido, me cabe la duda acerca del interés de fondo que tiene el diputado señor Monckeberg para que se apruebe el proyecto, ya que se ha acudido a un conjunto de subter- 
lo que respecta al procedimiento tutelar sufrió grandes modificaciones y negociaciones políticas para su aprobación. Nuestro objeto de estudio, asimismo, no fue ajeno a estas negociaciones y por poco se queda sin el reconocimiento legal que hoy tiene. Como se verá, la irrupción -a que hago referencia- de la garantía de indemnidad en el Derecho chileno y su desarrollo fue necesario, pero bastante tardía y esquiva comparada con la inclusión y reconocimiento de esta garantía en los ordenamientos jurídicos de los países más desarrollados, tanto en el derecho continental como en el common law.

Siendo la relación laboral el ejercicio de un poder privado sobre el otro ${ }^{9}$, se crea un escenario favorable para la vulneración de derechos y abusos de poder de aquel que tiene el poder de dirección sobre aquel que debe ser empleado en una actividad. El objeto de la indemnidad y su razón de ser, es decir, la injusticia que constituye el actuar en contra de un trabajador por haber reclamado este en contra de su empleador se vislumbra desde la promulgación del Reglamento 119 en el año 1963 de la OIT, referido a la terminación de la relación del trabajo por iniciativa del empleador ${ }^{10}$. Sin embargo, como explicaré en el transcurso del trabajo, en Chile no existía una garantía de indemnidad antes de año 2006, y sostengo que la inclusión de la garantía de indemnidad en el artículo 485 inciso 3 del Código del Trabajo chileno fue fortuita y por poco se queda sin reconocimiento legal.

Antes de proseguir es menester tener en cuenta la importancia social y cultural que constituye el trabajo, y a su vez la especialísima relación de poder que legitima el contrato de trabajo entre privados. En efecto, "en la conformación social que conocemos, los poderes del empresario o la empresa en cuanto poder privado constituyen una real amenaza para los derechos de la persona del trabajador, y ello se debe no por considerar tales poderes como intrínseca u ontológicamente insidiosos o perversos, sino, más sencillamente por cuanto, la lógica empresarial (sus principios econó-

fugios a fin de evitar que se aprueben normas específicas de fundamental importancia para que se logre el objetivo propuesto por el Gobierno. Sin embargo, estos son los temas -lo reitero y lo reiteraré en cada uno de los proyectos de esta naturaleza- en los cuales el Congreso da una señal de que en verdad estamos haciendo un debate serio y responsable sobre la igualdad y redistribución de la riqueza(...) Considero que la tramitación del proyecto ha demorado demasiado, dada la importancia social que tiene. Creo que el diputado señor Monckeberg no quiere que se apruebe, porque en la Comisión nos sometió a un conjunto de situaciones, incluso cuestionó su legalidad." Palabras de la Diputada Sra. Adriana Muñoz (PPD). Historia de LA Ley No 20.087 pp 332-333.

9 Gamonal (2009) 9

10 Reglamento No 119 OIT. Artículo 30 : "Entre las razones que no deberían constituir una causa justificada para la terminación de la relación de trabajo figuran los siguientes: c) presentar de buena fe una queja o participar en procedimientos entablados contra el empleador por razones de violaciones alegadas de la legislación". en http://www.ilo.org/ilolex/cgi-lex/convds. pl?R119. 
micos y valores normativos) actúa naturalmente como freno a la expresión de aquellos derechos (fundamentales), comprometiendo su desarrollo"11.

El Derecho del Trabajo otorga legitimidad a una relación de poder inherentemente compleja y vital, facultando el uso de potestades de mando y de dirección sobre la vida de otro, poniendo en clara desventaja al trabajador que se encuentra en situación de dependencia respecto a quien le provee el sustento material. Esta dependencia del trabajador va más allá de una simple relación contractual, prestación o tarea efectivamente hecha que se retribuye con una determinada remuneración. Esta situación especial de subordinación y dependencia "constituye un marco propio para la aparición de situaciones de represalia cuando el empresario utiliza de forma desviada su poder de dirección y su posición de superioridad para perjudicar al trabajador que hubiera presentado alguna reclamación en su contra" 12 .

Por tanto, la garantía de indemnidad es fruto de un Derecho del Trabajo lógico y concordante con la finalidad tutelar y protectora de la parte más débil: "frenar los eventuales abusos de una situación de poder que se rotula como de mando y de obediencia, y que es la misma lógica inscrita en el código genético de los derechos fundamentales" 13 .

\section{2) DESARROLLO CONCEPTUAL Y NORMATIVO DE LA GARANTÍA EN EL DERECHO COMPARADO Y EL ORDENAMIENTO JURÍDICO CHILENO}

Conceptualmente, la indemnidad es definida en su sentido natural y obvio como "estado o situación de quien está libre de dańo o perjuicio"14; en materia doctrinal, viene "a suponer la prohibición de cualquier género de represalia empresarial contra el trabajador, que traiga su causa de forma directa por el ejercicio por parte de este de su legítimo derecho a la tutela judicial efectiva, incluyendo determinados actos previos al propio proceso ${ }^{15 "}$.

11 CaAmaño, (2007) 17-18, citando a VALDÉS DAL RÉ, Fernando, Los derechos fundamentales de la persona del trabajador, ob.cit. p. 68.

12 Cavas Martínez, Faustino (2006) "La garantía de indemnidad del trabajador que presenta reclamaciones judiciales o extrajudiciales contra el empresario." En Aranzadi Social num. 4/2006, Editorial Aranzadi S.A. Pamplona. p. 2

UGARTE (2007). 58

Diccionario de la Lengua Española, Edición XXII, Editorial Espasa.

Estudios Laborales (2011) "Tutela por garantía de indemnidad." Ministerio de Justicia, Unidad de Defensa Laboral. p 3

"En ese caso, el derecho vulnerado -conocido en el derecho comparado como garantía de indemnidad-corresponde a la garantía del trabajador a no ser objeto de represalias por parte del empleador en el ejercicio de sus derechos laborales de cualquier naturaleza (fundamentales específicos e inespecíficos, legales o contractuales), de resultas o como consecuencia de las actuaciones de organismos públicos en la materia, tanto judiciales como administrativos. 
En el Código del Trabajo chileno, el legislador utiliza la palabra represalia al configurar legalmente la garantía de indemnidad y en este mismo sentido se utiliza la palabra retaliation y antiretaliation en el common law. Según la RAE, represalia significa "una respuesta, castigo o venganza a una agresión u ofensa". Debe advertirse, sin embargo, que la palabra represalia utilizada en el Código del Trabajo pareciera no ser la adecuada, ya que aquello implicaría natural y necesariamente una relación causal entre respuesta/ castigo del empleador a una determinada agresión/ofensa del trabajador. Aunque el concepto represalia es utilizado indiscriminadamente, su significado no debe ser subsumido en las situaciones fácticas que la garantía de indemnidad busca proteger.

La respuesta, castigo o venganza por parte del empleador en contra del trabajador no responde a una determinada agresión u ofensa, como se desprende del significado de represalia. Esta respuesta del empleador a una "agresión u ofensa" por parte del trabajador, constituye en sí una doble injusticia que la palabra represalia no representa en su significado: por un lado, el empleador ilegítima e irrevocablemente provoca daño al trabajador, por el solo hecho de haber ejercido legítimamente un derecho, producto de una aspiración de justicia; y por otro lado, el empleador ejerce en este caso sus potestades sin causa o razón, siendo la represalia ejercida únicamente por razonamientos de carácter subjetivo, emocionales o de venganza. En este sentido, todos los actos de represalia ejecutados por parte del empleador carecen de causa válida, ya que son retributivos de una "agresión" inexistente.

Volviendo al desarrollo normativo de la garantía, es el Tribunal Constitucional español el que desarrolla la garantía de indemnidad a partir del año 1993, desarrollo ligado a la garantía constitucional de tutela judicial efectiva o acceso a la jurisdicción. En efecto, "el derecho a la tutela judicial efectiva del artículo 24.1 CE no solo se satisface mediante la actuación de los jueces y tribunales, sino también a través de la garantía de indemnidad, lo que significa que del ejercicio de la acción judicial o de los actos preparatorios o previos a esta no pueden seguirse consecuencias perjudiciales en el ámbito de las relaciones públicas o privadas para la persona que los protagoniza. ${ }^{16 "}$

El fundamento normativo de la garantía de indemnidad en nuestro ordenamiento, proveniente del ordenamiento español, es la protección

Como ha destacado la doctrina, la garantía de indemnidad "vedaría al empresario la posibilidad de ocasionar dańo por el simple hecho de formular el trabajador una reclamación de derechos, pudiendo revestir los mecanismos de represalia empresarial distintas modalidades, como son las no renovaciones contractuales, discriminaciones retributivas, modificaciones de condiciones de trabajo, traslados, sanciones disciplinarias y despidos". (Autor citando a Valle., F.A.) UGarte, José (2007), "La tutela de derechos fundamentales y el derecho del trabajo: de erizo a zorro." Revista de Derecho, Universidad Austral de Chile, vol. XX. 
del derecho a la tutela judicial efectiva. Se transforma la garantía de indemnidad en una "proscripción de resultados lesivos para el trabajador a consecuencia del ejercicio de la tutela judicial efectiva, traducido en actos jurídicos propiamente tales y algunos que pueden ser antecedentes de los mismos" 17 .

En Chile, los tribunales reconocen expresamente que el fundamento constitucional de la garantía de indemnidad se encuentra directamente en el artículo 19 no3 de la Constitución Política de la República, es decir, la igual protección de la ley en el ejercicio de los derechos. Dicha norma, cuyo núcleo básico se refiere a la garantía constitucional de la tutela judicial efectiva, es complementada en cuanto a su alcance por el contenido de los tratados internacionales ratificados por Chile y que se encuentran vigentes, especialmente el artículo 25 de la Convención Americana de Derechos Humanos ${ }^{18}$.

En la doctrina comparada se distinguen dos clasificaciones de la garantía de indemnidad, que se recoge del análisis jurisprudencial de las sentencias del Tribunal Constitucional español. Es ella quien ha acuñado dos conceptos de garantía de indemnidad ${ }^{19}$.

La concepción de garantía de indemnidad estricta está relacionada con el derecho del trabajador a ejercer la tutela judicial efectiva, siendo posible que el derecho a la acción se extienda a otros tipos de actuaciones procesales no necesariamente unidas a las relaciones laborales. "Sobre la base de esta primera acepción la garantía de indemnidad constituiría una manifestación particular del contenido básico del derecho a la tutela judicial efectiva previsto en el art. 24.1 CE (LA LEY 2500/1978), y con ella se pretende evitar que el ejercicio de una acción judicial por un trabajador en contra su empresario lleve aparejada, directa o encubiertamente, una represalia que le perjudique en el ámbito de su relación laboral. Y es que de nada serviría el reconocimiento de acceso a la tutela judicial, si como consecuencia de ello, y por sí mismo, se posibilitara que quien acciona puede sufrir una lesión (con consecuencias jurídicas) por ejercitar un derecho" 20 . "Lo más seguro es que de los términos sumamente amplios y generosos con los que aparece formulada la doctrina sobre la indemni-

17 Estudios Laborales (2011) 3.

18 Establece que" toda persona tiene derecho a un recurso sencillo y rápido o a cualquier otro recurso efectivo ante los jueces o tribunales competentes, que la ampare contra actos que violen sus derechos fundamentales reconocidas por la Constitución, la ley, o la presente convención, aun cuando tal violación sea cometida por personas que actúen en ejercicio de sus funciones oficiales." Convención Americana sobre Derechos Humanos, en http:// www.oas.org/juridico/spanish/tratados/b-32.html contra el empresario" Relaciones Laborales, No9, Sección Doctrina, Quincena del 8 al 23 de Mayo 2005, Año XXI, tomo I, Editorial La Ley p 1. 
dad se puede concluir que la misma opera con independencia del orden jurisdiccional y del tipo de tutela solicitada judicialmente irradiándose a toda manifestación del derecho a tutela judicial efectiva, y no solo a la reclamación de derechos laborales ante los órganos del orden jurisdiccional social" 21 .

La concepción amplia del término indemnidad, en cambio, se refiere a la prohibición empresarial de represalia ante el ejercicio del trabajador de cualquier otro derecho fundamental distinto al de tutela judicial efectiva, como la libertad de expresión, la libertad de información, el derecho a huelga y el derecho de libertad sindical" 22 .

La indemnidad en nuestro Código del Trabajo solo se debe entender en un sentido estricto en cuanto a que su extensión y amplitud ya está definida y limitada por el marco legal de la norma. El artículo 485 inciso $3^{\circ}$ entiende que solo serán objeto de protección los derechos fundamentales protegidos por la acción de tutela ${ }^{23}$, y que se entienda como una acción de represalia ejercida en contra de los trabajadores, en razón o a consecuencia de la labor fiscalizadora de la Dirección del Trabajo o por el ejercicio de acciones judiciales.

En el ordenamiento jurídico estadounidense el derecho a no ser objeto de represalias tiene un fundamento normativo diferente, que se construye esencialmente en el derecho que tiene toda persona a no ser objeto de discriminación en el ámbito laboral, es decir, la igualdad (de oportunidades) ante la ley. Es importante hacer esta distinción, aunque exista un vínculo muy estrecho entre la tutela antidiscriminatoria (fundamento de la indemnidad en el common law) y el ejercicio de la tutela judicial efectiva. Tal como lo plantea de manera muy clara Valle, "la protección adecuada contra las represalias empresariales constituye un elemento imprescindible para el logro de los fines y objetivos del vasto conjunto de normas dedicadas a la salvaguarda de la igualdad de trato y la erradicación de la discriminación" ${ }^{24}$. Sin embargo, la misma jurisprudencia españo-

21 "Respecto a esta clasificación, no puede negarse que se trata esta de una distinción hasta cierto punto artificial si se tiene en cuenta que el propio conjunto de derechos laborales, tanto ordinarios como constitucionales, depende, en su ejercicio, de la eficaz garantía de protección jurisdiccional o si se quiere, del acceso a la tutela judicial efectiva (6), por lo que el desconocimiento de la garantía de indemnidad, supondría indirectamente una vulneración a los mismos" Cavas (2006) 4.

22 VAlle (2005) 1.

23 Los derechos fundamentales protegidos por la acción de tutela se encuentran enumerados en el artículo 485 inciso primero del Código del Trabajo: Artículo 19No1, inciso primero, siempre que su vulneración sea consecuencia directa de actos ocurridos en la relación laboral, $4^{\circ}, 5^{\circ}$, en lo relativo a la inviolabilidad de toda forma de comunicación privada, $6^{\circ}$, inciso primero, 12 , inciso primero y 16 , en lo relativo a la libertad de trabajo, el derecho a su libre elección y a lo establecido en el inciso cuarto, cuando aquellos derechos resulten lesionados en el ejercicio de las facultades del empleador. 
la ha optado por "separar los planos de la igualdad y de la indemnidad, omitiendo un pronunciamiento sobre si el derecho fundamental a la no discriminación incluye también la defensa frente a actos de represalia, y ha otorgado el amparo (de indemnidad) exclusivamente en el derecho a la tutela judicial efectiva" 25 .

El desarrollo del derecho a no ser objeto de represalias en el common law se fundamenta en la ley de derechos civiles de 1964, The Civil Rights Act of 1964 and the Equal Employment Opportunity Commision, ley referida a la igualdad de oportunidades en el trabajo, prohibiendo actos de discriminación laboral basada en la raza, color, religión, origen -entre otrasmediante el señalamiento de diversas hipótesis conductuales por parte del empleador que constituirían prácticas de discriminación.

El título VII de dicha ley, denominado Title VII Antiretaliation Provisions $^{26}$, es una norma contenida bajo el título de otras prácticas ilegales en el trabajo (other unlawful employment practices). Específicamente señala la represalia como un acto de discriminación (Discrimination for making charges, testifying, assisting, or participating in enforcement proceedings), describiendo qué trabajadores son legitimarios activos de la acción, y bajo qué hipótesis su conducta será objeto de protección de una posible represalia por parte del empleador. Cualquier trabajador que se encuentre en la situación descrita en la norma, es titular de la acción antirrepresalia (Antiretaliation).

Dicha norma contiene dos situaciones fácticas que son definidas claramente: En la doctrina son conocidas como la cláusula de oposición (opposition clause) y cláusula de participación (participation clause). La primera establece que será una conducta ilegal del empleador discriminar a cualquiera de sus trabajadores (la norma incluye trabajadores sindicalizados, practicantes, etc.) por haberse opuesto a este en el ejercicio de una práctica ilegal o discriminatoria. La cláusula de participación, en cambio, expone que será ilegal la conducta del empleador cuando discrimine a un trabajador por haber acusado, atestiguado, asistido, o participado de

\footnotetext{
25 VALLE (2005) 2.
}

26 (a) Discrimination for making charges, testifying, assisting, or participating in enforcement proceedings. It shall be an unlawful employment practice for an employer to discriminate against any of his employees or applicants for employment, for an employment agency, or joint labor-management committee controlling apprenticeship or other training or retraining, including on-the-job training programs, to discriminate against any individual, or for a labor organization to discriminate against any member thereof or applicant for membership, because he has opposed any practice made an unlawful employment practice by this subchapter, or because he has made a charge, testified, assisted, or participated in any manner in an investigation, proceeding, or hearing under this subchapter. Title 42, Chapter 21, Subchapter VI, \$2000.e-3. Obtenido de U.S Code, Law School, Cornell University, extraído de la página http://www.law.cornell.edu/uscode/42/usc_sup_01_42.html 
cualquier manera en una investigación, proceso, o audiencia en contra del empleador por discriminación.

¿Se podría subsumir la hipótesis fáctica de la opposition/participation clause en alguna de las calificaciones que hace la doctrina continental de la garantía de indemnidad? Desde luego, ambas cumplen con la misma función de prevenir revanchas empresariales, pero la primera no descansa en el derecho a la tutela judicial efectiva, sino que el verbo rector de su regulación es la no discriminación en el empleo. No es coincidencia que el órgano administrativo fiscalizador del cumplimiento de la ley sea la Comisión de Igualdad de Oportunidades en el Empleo EEOC (Equal Employment Opportunity Commission). Pareciera ser que se limita a proteger la igualdad de oportunidades en el empleo y la no discriminación, y no todos los derechos fundamentales. Sin embargo, a pesar de que tutela únicamente las actitudes no discriminatorias en el empleo, su regulación es más amplia y desarrollada que la símil chilena. Ejemplo de esto es que existen numerosas normas que prohíben específicamente la represalia en diversas situaciones o hipótesis de conducta.

Por ejemplo, encontramos por lo menos 17 leyes distintas que amparan al trabajador en contra actos de represalia por parte del empleador, facultando al afectado reclamar y denunciar los hechos constitutivos de represalia a la Administración de Seguridad y Salud Ocupacional, OSH (Occupational Safety and Health Act) de $1970^{27}$, cuyo objeto es asegurar la protección de la salud de los trabajadores y prevenir accidentes del trabajo.

El trabajador que siente que ha sido discriminado por el empleador por ejercer derechos de seguridad o salud, puede presentar un reclamo o queja ante la OSHA para la realización de una labor fiscalizadora por parte de esta. Esta misma define una gran cantidad de formas de discriminación por presentar una queja, cosa que no hace específicamente el articulado chileno, sino que las situaciones se dejan al criterio interpretativo de los jueces.

Formas de discriminación por presentación de una queja ante la OSHA pueden ser: despido, remoción, traslado, la suspensión, eliminación de la posibilidad de horas extraordinarias o de una promoción, la exclusión de horas normales, la asignación a un turno no deseado, la denegación de beneficios como días de vacaciones o enfermedad, las listas negras compartidas con otros empleadores, la supresión de alojamiento de compañía, los perjuicios al crédito con bancos o cooperativas de crédito y reducción de paga u horas.

Ejemplos:

a) Le está prohibido al empleador ejercer represalias en contra del trabajador discapacitado, que en virtud de la Ley ADA (Americans with 
Disabilities Act) solicite o requiera de manera evidente ciertos beneficios u acomodaciones (reasonable accommodations) a cargo del empleador para el ejercicio de su trabajo. Esta acomodación o proceso de adaptación del trabajador con discapacidad incluye una amplia gama de posibilidades, que van desde la construcción de infraestructura para el trabajador discapacitado, reestructuración de la labor ejercida, adquisición de equipos especializados y herramientas, o cualquier medida tendiente a lograr un ambiente de trabajo que permitan al discapacitado cumplir con su labor.

b) En el mismo sentido, expresamente se previenen represalias en contra de los denominados "whistleblowers" en las clausulas contenidas en la Ley $\mathrm{SOX}^{28}$ (the Sarbanes-Oxley Act)". El whistleblower, es "aquella persona que dentro de una organización pone de manifiesto alguna irregularidad, con lo cual se hacen destinatarios de represalias por parte de los demás miembros de la misma ${ }^{29}$ ". Esta ley federal, referida específicamente a los instrumentos financieros y sociedades anónimas, protege al trabajador que denuncia un hecho criminal o fraudulento a las autoridades y/o entrega información útil y veraz relacionada con la ejecución (o posible ejecución) de un delito corporativo. Se sanciona de manera gravísima, con multas y prisión hasta de 10 años, a aquellos empleadores que ejercen actos de represalias en contra de estos sujetos. Y respecto al trabajador, la ley obliga a la reincorporación del trabajador a la misma posición jerárquica en la empresa y antigüedad, pagar indemnizaciones de carácter compensatorio e intereses, entre otros.

\section{3) DESARROLlO DE LOS ELEMENTOS ESENCIALES DE LA GARANTÍA EN LA JURISPRUDENCIA CHILENA Y ESTADOUNIDENSE}

\section{1.) AMPLITUd DE PROTECCIÓN (LEGITIMACIÓN ACTIVA EXTENSA)}

La capa protectora de la garantía es bastante amplia, tanto en el ordenamiento jurídico chileno como en el estadounidense, no solo amparando al trabajador que de manera directa ejerza acciones judiciales

Under the Corporate and Under the Corporate and Criminal Fraud Accountability Act, Title VIII of the Sarbanes-Oxley Act (SOX), employees of certain publicly traded companies, companies with certain reporting requirements with the Securities and Exchange Commission (SEC), and their contractors, subcontractors, and agents may file complaints with OSHA if they believe that they have experienced discrimination or retaliation for reporting alleged violations of the federal mail, wire, bank, or securities fraud statutes, any rule or regulation of the SEC, or any other provision of federal law relating to fraud against shareholders. http://www.mondaq.com/unitedstates/article.asp?articleid=74424 
contra el empleador o que recurra ante la autoridad administrativa, sino que también protege a los trabajadores que indirectamente son objeto de represalia; por ejemplo, en el caso en que un trabajador atestigüe a favor de otro en contra del mismo empleador o defienda explícitamente los derechos de otros trabajadores involucrados.

Ahora, esta legitimación activa amplia en nuestro ordenamiento se debe al complemento que existe entre la norma del artículo 489 inciso $1^{\circ}$ del Código del Trabajo, y el análisis interpretativo de la norma y de su finalidad que han hecho los Tribunales de Justicia. Primero, la garantía de indemnidad no se encuentra regida por las reglas limitativas de legitimación activa que se exigen en el procedimiento de tutela laboral, y además los tribunales han hecho extensivo su alcance a través de un análisis de normas constitucionales e internacionales, "ya que de no ser así, se desnaturalizaría gravemente la institución ${ }^{30 "}$.

El análisis del alcance del artículo 485 inciso $3^{\circ}$, referido a la indemnidad, es desarrollada de manera clara por el Juzgado de Letras del Trabajo de La Serena, en la sentencia definitiva dictada en la causa T13-2009 ${ }^{31}$. En el juicio mencionado, la demandante, trabajadora de una tienda de óptica, demandó a su empleadora de tutela laboral, debido a una supuesta vulneración a la garantía de indemnidad. El día 15 de mayo de 2009 la actora fue despedida por necesidades de la empresa, específicamente la racionalización permitida en el artículo 161 inciso $1^{\circ}$ del código del ramo. Sin embargo, el verdadero motivo de despido fue una represalia ejercida en contra de la actora por haber atestiguado a favor de su hermana en un juicio laboral en contra de la misma empleadora un día antes de ser despedida, el 14 de mayo de 2009.

El Tribunal, en el considerando Séptimo de la sentencia, no deja lugar a dudas sobre la amplitud de protección de la garantía de indemnidad. "Cabe señalar que la norma transcrita (Artículo 485 inciso III) es lo suficientemente clara en su redacción de manera que, a juicio de esta sentenciadora, no cabe duda alguna de que es además "lo suficientemente amplia" para que se entienda que esta garantía protege no solo al trabajador que recurre ante la autoridad administrativa o al órgano jurisdiccional en el ejercicio de sus derechos, sino también en el caso de marras, cuando lo hace en calidad de testigo de otro trabajador o en defensa de derechos de otros trabajadores, sea o no representantes de ellos ${ }^{32}$ ".

En Estados Unidos, recientemente (2009) la Corte Suprema amplió la protección de la garantía de indemnidad, extendiéndola de manera expresa al trabajador que se ha "opuesto" de cualquier manera a prácticas

\footnotetext{
30 RIT T -13-2009, Sentencia definitiva, Considerando Séptimo.

31 RIT T.13.2009, Sentencia definitiva, Considerando Séptimo.

32 RIT T-13-2009, Sentencia definitiva, Considerando Séptimo.
} 
discriminatorias, no siendo necesario haber denunciado, instigado una investigación o haberse opuesto a través de medios formales a una práctica discriminatoria del empleador.

En el caso Crawford v. Metropolitan Goverment of Nashville and Davidson City, el empleador inició una investigación interna en contra de un funcionario de alto cargo administrativo, Gene Hughes, por reiterados rumores de acoso sexual (sexual harrasment). Entre las aristas de la investigación, la funcionaria Veronica Frazier, del departamento de recursos humanos, preguntó entre los trabajadores si alguien había sido testigo de alguna actitud impropia por parte del director. Tres testigos reportaron en el interrogatorio interno que habían sido acosadas sexualmente por Hughes de diversas maneras. Una de ellas, la demandante, Vicky Crawford, declaró que en varias ocasiones había sido objeto de actos de significancia sexual, incluyendo que en una ocasión Hughes entró en su oficina, le agarró la cabeza y la acercó a su entrepierna ${ }^{33}$.

Luego de finalizar la investigación, Metropolitan no tomó ninguna medida en contra de Hughes, y despidió a las 3 trabajadoras que acusaron haber sido acosadas sexualmente por Hughes. En el caso de Crawford, la institución alegó haberla despedido por malversación (embezzlement).

Ante el despido, Crawford demandó a Metropolitan alegando que su despido fue un acto de represalia por haber acusado al director Hughes por conductas de acoso sexual en la investigación interna. La Corte del Distrito de Tennessee ( $1^{\text {a }}$ Instancia) desechó el reclamo arguyendo que ella no estaba protegida por la norma antirrepresalia (opossition clause) por no haberse opuesto a la conducta o iniciado un reclamo o denuncia, sino que había únicamente respondido preguntas en una investigación interna iniciada por otra persona ${ }^{34}$.

La Corte de Apelaciones (Court of Appeals), confirmó el fallo de primera instancia, aduciendo las mismas razones que el tribunal inferior, e incluso declaró que las preguntas hechas a las trabajadores por el departamento de recursos humanos no cumplían con las formalidades de una investigación interna. Para estar protegido por la ley antirrepresalia requiere oponerse a la actitud discriminatoria del empleador de manera activa y fehaciente. En este caso, Crawford no inició o impulsó una denuncia o

33 Crawford described several instances of sexually harassing behavior: once, Hughes had answered her greeting, "Hey Dr. Hughes, what's up?" by grabbing his crotch and saying "'You know what's up"; he had repeatedly "put his crotch up to her window"; and in one occasion he had entered her office and "grabbed her head and pulled it to his crotch." Supreme Court of United States, No 06-1595, Vicky S. Carwford, Petitioner, V. Metropolitan Government of Nashville and Davidson County, Tennessee. En http://www.ca6. uscourts.gov/opinions.pdf/06a0828n-06.pdf p 2.

34 "It held (District Court) could not satisfy the opposition clause because she had not "instigated or initiated any complaint", but "had merely answered questions by investigators in an already- pending internal investigation, initiated by someone else" 
queja antes de su participación en la investigación, ni realizó alguna acción posterior a la investigación o antes del despido ${ }^{35}$.

La Corte Suprema finalmente revoca la sentencia de la Corte de Apelaciones, explicando que para ser objeto de protección de la garantía de indemnidad no es necesario instigar o iniciar un reclamo para "oponerse" a una práctica discriminatoria. Mientras que el trabajador comunique su creencia o conocimiento de que un acto discriminatorio ha ocurrido, se ha "opuesto" a dicho acto discriminatorio, siendo suficiente esta comunicación verbal para ser objeto de la norma anti represalia (opposition clause).

\section{2.) RELACIÓN CAUSA- EFECTO (CONEXIÓN TEMPORAL)}

Otro elemento básico para que concurra la vulneración de la garantía de la indemnidad es la conexión temporal que debe existir entre la denuncia y el hecho del despido. Debe haber una clara relación causa-efecto entre el ejercicio de la acción del trabajador, tanto judicial como administrativa, y la represalia por parte del empleador.

En el caso Henry $O^{\prime}$ Neal v. Ferguson Construction Company ${ }^{36}$, el trabajador Henry O'Neal, de raza negra, con 32 años de servicio y 29 de ellos encargado del cuidado y mantención de la flota vehicular de la empresa, interpone un reclamo ante la EEOC (Equal Employmnent Opportunity Comission) en contra de su empleador por discriminación racial el día 22 de octubre de 1996. Según dijo, era objeto de discriminación por medio de comentarios y chistes raciales, incluso, por parte de altos funcionarios de la empresa: un testigo en el juicio declaró que el ex presidente de la compañía Ferguson, le había comentado que "una vez que se fuese Henry de la compañía, sería el último negro hijo de puta en trabajar allí37".

35 "Crawford did "not claim to have instigated or initiated any complaint prior to her participation in the investigation, nor did she take any further action following the investigation and prior to the firing." p 3

Henry O 'Neal v. Ferguson Construction Company http://openjurist.org/237/f3d/1248/henryoneal-v-ferguson-construction-company

37 “O’Neal worked for Ferguson for approximately thirty-two years. Until a few days before his termination, O'Neal spent twenty-nine of those years as the sole person responsible for maintaining and servicing Ferguson's vehicle fleet. For most of the twenty-nine years, O’Neal worked a split shift from 5:00 a.m. until 10:00 a.m. and from 4:00 p.m. until 9:00 p.m. In the early 1990s, Mark Weiser became president of Ferguson. A former Ferguson employee testified at trial that sometime in 1994 Weiser told him that when he "got rid of Henry," he would never have another "black son of a bitch" working at Ferguson. O'Neal testified that around the same time, Weiser stopped interacting with him. O'Neal further testified that Nat Rendon, a Ferguson vice president who was responsible for hiring and firing employees, regularly told racial jokes which included derogatory, offensive terms to African-Americans. O'Neal v Ferguson Construction Company. II. Background, puntos 2-9. 
A comienzos de enero de 1997, dos meses después de notificado el reclamo, la empresa decide reducir la jornada de trabajo de O'Neal, de 56 a 33 horas semanales y se comienza a reasignar su trabajo a otros trabajadores. Un segundo reclamo ante la EEOC es interpuesto por O'Neal, debido a que consideraba que esta reducción de horas y de naturaleza de trabajo era una forma de represalia por parte de la empresa.

El día 10 de septiembre de 1997 la empresa Ferguson recibe "the right to sue notice (aviso con derecho a demandar) ${ }^{38 "}$, por parte de la EEOC. El 15 de septiembre O'Neil es trasladado a trabajar en el depósito de suministros de la empresa. El día 18 de septiembre del mismo año el abogado de $\mathrm{O}^{\prime} \mathrm{Neal}$ le escribe una carta a Ferguson exigiendo que su cliente sea vuelto a su posición de trabajo inicial, y con la jornada de trabajo completa. El día siguiente del recibo de aquella carta es despedido.

En este caso, el Tribunal enumera cuáles son los requisitos para configurar un acto de represalia por parte del empleador: a) El demandante debe probar que se opuso a un acto de discriminación por parte del empleador (opposed clause). b) Que sufrió un acto adverso por parte del empleador. c) Hay una relación causal entre su oposición protegida y el acto adverso del empleador ${ }^{39}$.

Si bien la empresa Ferguson y su defensa trataron de establecer que no hubo conexión causal entre los reclamos a la EEOC y el despido debido a la gran cantidad de meses que transcurrieron entre el primer reclamo

38 "Right to sue notice" (Aviso de derecho a demandar) es una carta enviada por la OECC a ambas partes que están bajo una investigación o fiscalización por presunta discriminación. En el caso de que existan antecedentes fundados de que la discriminación tuvo lugar, se envía esta carta, que da derecho al trabajador a demandar en juicio al empleador en un plazo de 90 días desde que se recibe.

"There are two types of letters generally referred to as "right to sue" sent out by the EEOC during the complaint resolution process, though they have formal different names and different meanings. Before you can go forward with a lawsuit under Title VII, you must have a "right to sue" letter in hand.

If the EEOC determines that there is no reasonable cause to believe that discrimination occurred, you will be issued a letter called a Dismissal and Notice of Rights that tells you that you have the right to file a lawsuit in federal court within 90 days from the date of receipt of the letter. The employer will also receive a copy. Even though this letter will not support your claim, it establishes your right to bring a lawsuit and try to prove your claim in court. Where there is reasonable cause to believe discrimination has occurred, both parties have been issued a Letter of Determination, and conciliation has failed, EEOC has the authority to file a lawsuit on your behalf in federal court. But the cases where the agency files a lawsuit are very rare. If the EEOC decides not to litigate in your behalf (by far the most common outcome), you will receive a Notice of Right to Sue outlining your right to file a private lawsuit in federal court within 90 days from receipt of the letter.

http://www.sexdiscrimination.org/Process\%20FAQ_files/Page466.htm

39 To establish a prima facie case of retaliation, O'Neal must establish that: (1) he engaged in protected opposition to discrimination; (2) he suffered an adverse employment action; and (3) there is a causal connection between the protected activity and the adverse employment action. See Kendrick v. Penske Transp. Srvs., Inc., 220 F.3d 1220, 1234 (10th Cir. 2000); http://openjurist.org/237/f3d/1248/henry-oneal-v-ferguson-construction-company 
y el segundo, fueron condenados en cuanto a haberse efectuado actos de represalia en contra del trabajador.

En la jurisprudencia chilena los mismos requisitos de relación causal son exigidos para dar lugar a la garantía de indemnidad del artículo 485 inciso $3^{\circ}$. Ante el Juzgado de Letras del Trabajo de Temuco, causa Rol T-8-2010, una trabajadora interpone una denuncia por discriminación de género y desigualdad de remuneración en contra de su empleador, con fecha 5 de noviembre de 2009.

Esta denuncia derivó en una fiscalización de dicho órgano administrativo 4 días después de la interposición de la denuncia, es decir, el 9 de noviembre de 2009. Después de dicha fiscalización, la Inspección del Trabajo no aplicó a la empresa sanciones administrativas de ningún tipo, sino que realizó una instrucción de carácter meramente administrativo. Las conclusiones arribadas en este instructivo, señalaban -entre otrasque había indicios de vulneración del derecho a la no discriminación y al principio de igualdad de las remuneraciones. Esta denuncia significó para la empresa una fiscalización instructiva y la obligatoriedad de concurrir a mediación. La actora, después de volver a trabajar luego de una licencia médica, es despedida al día siguiente, argumentándose necesidades de la empresa.

La conexión de temporalidad entre la denuncia interpuesta y el despido es valorada por el Tribunal como un indicio de vulneración a la garantía de indemnidad. "Que otro indicio es la temporalidad que media entre la fecha de la fiscalización realizada por la Inspección del Trabajo y la citación a la mediación, y la fecha de despido de 19 de enero de 2010, al día siguiente de volver al trabajo después de una licencia médica, donde transcurren 14 días 40 ".

"Que es indudable que existe relación de causalidad entre la denuncia presentada por la actora, que trajo como consecuencia la investigación de la Inspección del Trabajo, que arrojó una vulneración de derechos fundamentales por razones de sexo y remuneracionales, y el hecho del despido(...) Dicha conexión temporal permite establecer que la empleadora tomó la decisión de poner término al contrato de trabajo por el malestar que le provocó la denuncia, fiscalización y posterior citación a una mediación $^{41}$ ". Debe necesariamente haber una relación de acción-represalia, y una debe ser directa e inmediata consecuencia de la otra.

40 Causa RIT T-8-2010, “Aros Sandoval c/ Asociación Cristiana de jóvenes- YMCA Temuco". S.J.L. del Trabajo de Temuco. Considerando Noveno, en www.poderjudicial.cl

41 RIT T-8-2010, Sentencia Definitiva, Considerando Noveno. 


\section{5) ConClusión}

El presente trabajo, realizado a través de la comparación y análisis de la garantía de indemnidad y su desarrollo en el Derecho chileno y comparado, especialmente el common law estadounidense, tiene por objeto tratar de resolver dos grandes interrogantes, además de un análisis acucioso de la misma. La primera dice relación con el origen de la garantía de indemnidad en nuestro ordenamiento jurídico, y la segunda con el rol judicial en la utilización y reconocimiento de la garantía.

La inclusión de la garantía de indemnidad en nuestro ordenamiento jurídico pareciera ser un efecto casual y bastante tardío comparado con su regulación normativa en los tratados de la OIT y en el derecho comparado. Tal como se mencionó en la parte principal del trabajo, ya en el año 1963, a través de la promulgación del Reglamento 119, se intuía la grave injusticia que constituía la venganza por parte del empleador en contra del trabajador por haber reclamado este en su contra. Posteriormente en el Convenio 158 de la OIT del ańo $1982^{42}$ se ratifica este hecho, al establecer de manera clara y expresa que no constituye causa justificada de despido "presentar una queja o participar en un procedimiento entablado contra un empleador por supuestas violaciones de leyes o reglamentos, o recurrir ante las autoridades administrativas competentes".

Sin embargo, el Convenio 158 de la OIT no ha sido ratificado por nuestro país, y por lo tanto no tiene efecto vinculante. Es simplemente una declaración de buena voluntad y un apoyo doctrinario y quizás interpretativo $^{43}$, pero no tiene asidero legal en nuestra legislación conforme a lo establecido en el artículo $5^{\circ}$ inciso $2^{\circ}$ de la Constitución Política.

42 En el artículo 5 se incluye una lista no exhaustiva de los motivos que no constituirán causa justificada de despido. Esos motivos que no constituyen causa justificada son un reflejo de la protección que confieren otros instrumentos de la OIT. Entre los motivos que no constituirán causa justificada de despido a tenor del artículo 5 figuran los siguientes: i) la afiliación a un sindicato o la participación en actividades sindicales fuera de las horas de trabajo o, con el consentimiento del empleador, durante las horas de trabajo; ii) ser candidato a representante de los trabajadores o actuar o haber actuado en esa calidad; iii) presentar una queja o participar en un procedimiento entablado contra un empleador por supuestas violaciones de leyes o reglamentos, o recurrir ante las autoridades administrativas competentes; iv) la raza, el color, el sexo, el estado civil, las responsabilidades familiares, el embarazo, la religión, las opiniones políticas, la ascendencia nacional o el origen social, y v) la ausencia del trabajo durante la licencia de maternidad. La Recomendación complementa esta lista con otros dos motivos: i) la edad, sin perjuicio de la legislación y la práctica nacionales con respecto a la jubilación, y ii) la ausencia del trabajo debido al servicio militar obligatorio o al cumplimiento de otras obligaciones cívicas, en conformidad con la legislación y la práctica nacionales. Nota sobre la Convenio No 158 OIT y Reglamento 166 sobre la terminación del contrato de trabajo. CONVENIO 158 OIT, en http://www.uco.es/organiza/personal/ sindicatos/cgt/pages/legislacion/sociales/Convenio-158-OIT.pdf

43 "El derecho a no ser objeto de represalias laborales, o garantía de indemnidad, cuyo fundamento es la garantía constitucional de la tutela judicial efectiva, prevista en el artículo 25 de la Convención Americana de los Derechos Humanos y en el artículo 5 del Convenio 
¿Por qué Estados Unidos ha concretado la idea de indemnidad hace más de 5 décadas? ¿Por qué Chile reguló este derecho hace solo 5 ańos? El atraso de la regulación chilena en incorporar esta garantía tan necesaria y tan afincada en la realidad es patente, y el hecho que no fue considerada como primordial en el proyecto de ley No20.087 es una interrogante que queda sin respuesta. En Chile la garantía de indemnidad no ha sido objeto de gran desarrollo doctrinal. Hay una clara falta de literatura académica desarrollada por autores chilenos, lo que ha dado lugar a que los tribunales chilenos fundamentan la sentencia con la doctrina española y sus autores. No hay fallos importantes de la Corte Suprema o del Tribunal Constitucional a este respecto.

¿Se podría sostener, por tanto, que la inclusión de la garantía de indemnidad en nuestro ordenamiento es quizás un hecho fortuito, un producto de una negociación política por sobre una decisión técnica?

La verdad es que no sería sorprendente. El mensaje de la Ley No 20.087 no contenía mención alguna sobre la garantía de indemnidad, y solo en el segundo trámite constitucional en el Senado se introdujo la norma que actualmente fundamenta esta garantía y que forma parte del Código del Trabajo ${ }^{44}$.

Los diputados Nicolás Monckeberg (RN) y Felipe Salaberry (UDI), en el Primer informe Comisión de Trabajo, Cuenta en Sesión 47, Legislatura 352, solicitan que se suprima todo el párrafo sexto, es decir, el procedimiento de tutela de derechos laborales ${ }^{45}$. Lo mismo ocurre en el Primer informe de Comisión Trabajo en el Senado, en donde los senadores RN Baldo Prokurica, Sergio Romero y Antonio Horvath, y el senador Jaime Orpis (UDI) en las indicaciones al proyecto de ley 20.087, solicitaron derechamente la eliminación de dicho párrafo sexto ${ }^{46}$. Fue el Senador DC Eduardo Boeninger Kausel quien en las indicaciones (punto 228) solicita la incorporación de la garantía de indemnidad (Artículo 502 del Proyecto) y solo al finalizar el Segundo Informe de Comisión de Trabajo, se aprobó la transcripción de dicha garantía ${ }^{47}$.

Muestra de la discrepancia entre la ideología y la experticia técnica con que se votó el procedimiento tutelar son las palabras del entonces Senador

No 158 de la OIT sobre la terminación del contrato de trabajo, cuyo sentido se encuentre en obtener el trabajador del órgano jurisidiccional un amparo real del derecho del trabajo". RIT T-13-2009, Juzgado de Letras del Trabajo de La Serena, Considerando SÉPTIMO letra b), en www.poderjudicial.cl

44 Estudios Laborales (2011) 2.

45 Historia de la Ley No 20.087. p.123.

46 Historia de la Ley No20.087, Boletín de Indicaciones, punto 226 y 227. p 510-511.

47 Agregar la siguiente oración final: "En igual sentido se entenderán las represalias ejercidas en contra de trabajadores, en razón o como consecuencia de la labor fiscalizadora de la Dirección del Trabajo o por el ejercicio de acciones judiciales". (Mayoría de votos, cuatro a favor y una abstención. Indicación número 228)” Historia DE LA LeY No 20.087 p. 695. 
Bombal (UDI) en las sesiones del proyecto de Ley 20.087, quien delata la ingenuidad de ciertos sectores en reconocer derechos significativos para los trabajadores, haciendo descansar en la buena voluntad y deseos de un mundo mejor la solución para la compleja relación de poder que constituye una relación de trabajo, y que trasciende la sola voluntad de los participantes.

"El honorable Senador señor Bombal fundamentó su voto favorable, señalando que el proyecto está en la línea de lo que es la administración de justicia, necesaria también en el ámbito laboral. No obstante, le inquieta que en el procedimiento propuesto subyace un sentido de mayor protección hacia el trabajador, lo que, si bien es razonable respecto de las normas sustantivas del Código del Trabajo -que desarrollan el principio pro trabajador- no lo es en el ámbito judicial, puesto que en él las partes deben tener igualdad de derechos para un debido proceso. En una sociedad moderna, como la nuestra, las relaciones laborales también se han transformado, y empleadores y trabajadores no deben verse como adversarios, sino que en un plano de cooperación y de mutua confianza.

Su Señoría agrega que en las grandes empresas prácticamente no hay conflictos laborales. En mayor medida las dificultades se dan a nivel de la pequeña y mediana empresa y por ello hay que cuidar que la normativa propuesta no deje a los empleadores de este último sector en una suerte de indefensión, al no contar con las herramientas necesarias para una debida defensa judicial" 48 .

Habiendo entrado en vigencia la garantía de indemnidad (saltándose la barrera del por qué o el cómo entró en vigencia), podemos responder la segunda interrogante, referida al uso por parte de los tribunales de justicia de la garantía y cómo han configurado sus elementos. La comparación nos presenta una respuesta bastante positiva y esperanzadora. Son los jueces especializados en las materias propias del Derecho del Trabajo y su compromiso con el fortalecimiento de un Estado de Derecho Constitucional quienes han configurado los elementos distintivos de la garantía en nuestro ordenamiento, aquellos elementos definitorios de la figura. Estos han logrado dilucidar los elementos esenciales y concurrentes a toda a acción de tutela fundada en la vulneración del artículo 485 inciso $3^{\circ}$.

Con esto se ha demostrado la concordancia existente entre la jurisprudencia chilena y los tribunales estadounidenses en cuanto a los elementos de la garantía, a pesar de los pocos años de entrado en vigencia el proceso en nuestro país. Los elementos básicos de la garantía de la indemnidad están siendo aplicados por los jueces chilenos, y eso no puede ser otra cosa que un signo de desarrollo y especialización de los mismos en materias laborales. El artículo 485 inciso $3^{\circ}$ ha permitido crear un marco protector para los trabajadores chilenos, y es una herramienta útil y generosa para su utilización. Este norma, independiente de su origen, es una 
aspiración de justicia concreta en las relaciones labores, y mientras existan patrones y asalariados, su utilización será en muchos casos un abrigo de protección real y efectiva.

\section{BibLiOgRAFía}

- Boletín No 3.367-13. Historia de la Ley No20.087 "Sustituye el procedimiento laboral contemplado en el libro V del Código del Trabajo." www.bcn.cl (última vez revisada 10 de octubre de 2012).

- CaAmaño, Eduardo (2007) El derecho a la no discriminación en el empleo. Santiago, LexisNexis, $2^{\text {a }}$ Ed.

- Cavas Martínez, Faustino (2006) "La garantía de indemnidad del trabajador que presenta reclamaciones judiciales o extrajudiciales contra el empresario". En Aranzadi Social num. 4/2006, Editorial Aranzadi S.A. Pamplona.

- Estudios Laborales (2011) “Tutela por garantía de indemnidad". Ministerio de Justicia, Unidad de Defensa Laboral.

- Gamonal, Sergio (2009) El procedimiento de tutela de derechos laborales. Santiago, LegalPublishing Chile.

- Ugarte, José Luis (2004) "Los derechos fundamentales y relaciones laborales: en el mundo de las palabras", Anuario de Derecho del Trabajo y Seguridad Social No3/2004, Derechos Fundamentales, Homenaje al Profesor Patricio Novoa Fuenzalida, Sociedad Chilena de Derecho de Trabajo y de Seguridad Social.

- Ugarte Cataldo, José (2007) "La tutela de derechos fundamentales y el derecho del trabajo: de zorro a erizo". En Revista de Derecho (Valdivia) Volumen XX-diciembre 2007.

- VAlle, Francisco (2005) "La garantía de indemnidad del trabajador por ejercitar acciones contra el empresario" Relaciones Laborales, No 9, Sección Doctrina, Quincena del 8 al 23 de mayo 2005, año XXI, tomo I, Editorial La Ley.

\section{CÓDIGOS Y JURISPRUDENCIA CITADA}

- Código del Trabajo Edición 2011, Editorial Jurídica.

- Convención Americana sobre Derechos Humanos, en http://www. oas.org/juridico/spanish/tratados/b-32.html (última revisión 13 noviembre 2011)

- Reglamento No 119 OIT en http://www.ilo.org/ilolex/cgi-lex/ convds.pl?R119. (última revisión 13 de mayo 2012)

- Supreme Court of United States, No 06-1595, Vicky S. Carwford, Petitioner, V. Metropolitan Government of Nashville and Davidson 
County, Tennessee. En http://www.ca6.uscourts.gov/opinions. pdf/06a0828n-06.pdf (última revisión 13 noviembre 2011)

- U.S Code, Law School, Cornell University, extraído de la página http://www.law.cornell.edu/uscode/42/usc_sup_01_42.html (última revisión 13 noviembre 2011)

- http://www.mondaq.com/unitedstates/article. asp?articleid=74424 (última revisión 13 noviembre 2011)

- Juzgado de Letras del Trabajo de Temuco (2010) Causa RIT T-82010, "Aros Sandoval c/ Asociación Cristiana de jóvenes- YMCA Temuco". Sentencia definitiva, considerando noveno, en www. poderjudicial.cl (última revisión 13 de mayo 2012)

- Juzgado de Letras del Trabajo de La Serena (2009) Causa RIT T-132009, Sentencia definitiva, considerando séptimo. (última revisión 13 de mayo 2012)

- Henry O'Neal v. Ferguson Construction Company http://openjurist. org/237/f3d/1248/henry-oneal-v-ferguson-construction-company

- http://www.sexdiscrimination.org/Process\%20FAQ_files/Page466. htm (última revisión 13 noviembre 2011)

- Kendrick v. Penske Transp. Srvs., Inc., 220 F.3d 1220, 1234 (10th Cir. 2000); http://openjurist.org/237/f3d/1248/henry-oneal-vferguson-construction-company (última revisión 13 noviembre 2011) 